\title{
Two-year Efficacy and Safety of Etanercept in Pediatric Patients with Extended Oligoarthritis, Enthesitis- related Arthritis, or Psoriatic Arthritis
}

\author{
Tamas Constantin, Ivan Foeldvari, Jelena Vojinovic, Gerd Horneff, Ruben Burgos-Vargas, \\ Irina Nikishina, Jonathan D. Akikusa, Tadej Avcin, Jeffrey Chaitow, Elena Koskova, \\ Bernard R. Lauwerys, Inmaculada Calvo Penades, Berit Flato, Maria Luz Gamir, \\ Hans-Iko Huppertz, Juan Jose Jaller Raad, Katerina Jarosova, Jordi Anton, Marie Macku, \\ William J. Otero Escalante, Lidia Rutkowska-Sak, Ralf Trauzeddel, Patricia J. Velez-Sanchez, \\ Carine Wouters, Joseph Wajdula, Chuanbo Zang, Jack Bukowski, Deborah Woodworth, \\ Bonnie Vlahos, Alberto Martini, and Nicolino Ruperto, for the Paediatric Rheumatology \\ International Trials Organisation (PRINTO)
}

\begin{abstract}
Objective. The main objective was to determine the 2-year clinical benefit and safety of etanercept (ETN) in children with the juvenile idiopathic arthritis (JIA) categories of extended oligoarthritis (eoJIA), enthesitis-related arthritis (ERA), or psoriatic arthritis (PsA).

Methods. CLIPPER was a 96-week, phase IIIb, open-label, multicenter study. Patients with eoJIA, ERA, or PsA received ETN $0.8 \mathrm{mg} / \mathrm{kg}$ once weekly (50 mg max) for up to 96 weeks. The proportions of patients reaching the JIAAmerican College of Rheumatology (ACR) 30/50/70/90/100 and inactive disease responses at Week 96 were calculated. Adverse events (AE) were collected throughout the study (intention-to-treat sample).

Results. There were 127 patients (eoJIA $n=60$, ERA $n=38$, PsA $n=29$ ) who received $\geq 1$ dose of ETN. The mean disease duration was 31.6 (eoJIA), 23.0 (ERA), and 21.8 (PsA) months. At Week 96, JIA ACR 30/50/70/90/100/inactive disease responses (95\% CI) were achieved by $84.3 \%(76.7,90.1)$, $83.5 \%(75.8,89.5), 78.7 \%(70.6,85.5), 55.1 \%(46.0,63.9), 45.7 \%(36.8,54.7)$, and $27.6 \%(20.0$, 36.2 ) of patients, respectively. The most common AE (no. events, events per 100 patient-yrs) overall were headache $(23,10.7)$, pyrexia $(12,5.6)$, and diarrhea $(10,4.6)$. The most common infections were upper respiratory tract infection $(83,38.6)$, pharyngitis $(50,23.2)$, gastroenteritis $(22,10.2)$, bronchitis $(19,8.8)$, and rhinitis $(17,7.9)$. No cases of malignancy, active tuberculosis, demyelinating disorders, or death were reported.

Conclusion. Over 96 weeks of therapy, ETN demonstrated sustained efficacy at treating the clinical symptoms of all 3 JIA categories, with no major safety issues. (First Release March 1 2016; J Rheumatol 2016;43:816-24; doi:10.3899/jrheum.150430)
\end{abstract}

Key Indexing Terms:

JUVENILE IDIOPATHIC ARTHRITIS ENTHESITIS-RELATED ARTHRITIS

EXTENDED OLIGOARTHRITIS ETANERCEPT
PSORIATIC ARTHRITIS CLINICAL TRIAL

From the Paediatric Rheumatology International Trials Organisation (PRINTO), Istituto G. Gaslini, Pediatria II-Reumatologia, PRINTO, Genoa, Italy.

Sponsored by Wyeth, which was acquired by Pfizer in October 2009. T. Constantin has received speaker's fees from or served as a consultant for Pfizer. J. Vojinovic has received honoraria from Pfizer. G. Horneff has received honoraria from Pfizer. I. Nikishina has received honoraria from Pfizer. T. Avcin has received speaker's bureau fees and honoraria from Pfizer. H.I. Huppertz has received honoraria from Pfizer. J. Anton has received honoraria from Pfizer. M. Macku has received honoraria from Pfizer. R. Trauzeddel has received fees from Pfizer. A. Martini has received speaker's bureau fees and honoraria from Amgen, Pfizer, and Takeda. $N$. Ruperto has received speaker's bureau fees and honoraria from Amgen, Pfizer, and Takeda. The GASLINI Hospital, the public hospital where Dr. Ruperto and Prof. Martini work as fulltime employees, has received contributions to support the research activities of the PRINTO network (www.printo.it) from Pfizer Inc.; this money has been reinvested for the research activities of the hospital in a fully independent manner without any commitment to third parties. J. Wajdula, C. Zang, J. Bukowski, D. Woodworth, and B. Vlahos are all employees of Pfizer Inc. J. Wajdula is a Pfizer stockholder.

T. Constantin, $M D, P h D, 2 n d$ Department of Pediatrics, Semmelweis University, Budapest, Hungary; I. Foeldvari, MD, Hamburg Centre for Child and Adolescent Rheumatology, Hamburg, Germany; J. Vojinovic, $M D, P h D$, Clinic of Pediatrics, Clinical Centre, Faculty of Medicine, University of Nis, Serbia; G. Horneff, MD, Asklepios Clinic, Sankt Augustin, Germany; R. Burgos-Vargas, MD, Hospital General de Mexico, Mexico City, Mexico; I. Nikishina, MD, V.A. Nasonova Research Institute of Rheumatology, Moscow, Russia; J.D. Akikusa, MD, Royal Children's Hospital Melbourne, Parkville, Victoria, Australia; T. Avcin, MD, PhD, University Medical Centre Ljubljana, Pediatric Clinic, Ljubljana, Slovenia; J. Chaitow, MD, The Sydney Children's Hospital Network, Westmead, Sydney, Australia; E. Koskova, MD, PhD, National Institute of Rheumatic Diseases, Piestany, Slovakia; B.R. Lauwerys, MD, PhD, 
Institut de Recherche Expérimentale et Clinique, Université catholique de Louvain and Department of Rheumatology, Cliniques Universitaires Saint-Luc, Brussels, Belgium; I. Calvo Penades, MD, PhD, Hospital Universitario y Politécnico La Fe, Pediatric Rheumatology Unit, Valencia, Spain; B. Flato, MD, PhD, Oslo University Hospital, Department of Rheumatology, Oslo, Norway; M.L. Gamir, MD, Hospital Ramon y Cajal Unidad de Reumatologia Pediatrica, Madrid, Spain; H.I. Huppertz, MD, Klinikum Bremen-Mitte, Prof. Hess-Kinderklinik, Bremen, Germany, J.J. Raad, MD, Centro de Reumatologia y Ortopedia, Barranquilla, Atlantico, Colombia; K. Jarosova, MD, Revmatologicky Ustav, Prague, Czech Republic; J. Anton, MD, PhD, Pediatric Rheumatology Unit, Hospital Sant Joan de Déu, Universitat de Barcelona, Espluges (Barcelona), Spain; M. Macku, MD, Fakultni nemocnice Brno, Bohunice, Detska Nemocnice, Ambulance detske revmatologie detske kliniky, Brno, Czech Republic; W.J. Otero Escalante, MD, Servimed S.A.S.

Bucaramanga, Santander, Colombia; L. Rutkowska-Sak, MD, Instytut Reumatologii, Klinika i Poliklinika, Reumatologii Wieku, Rozwojowego, Warsaw, Poland; R. Trauzeddel, MD, HELIOS Klinikum Berlin-Buch Klinik für Kinder- und Jugendmedizin, Berlin, Germany; P.J. VelezSanchez, MD, Centro Integral de Reumatología e Inmunología SAS CIREI SAS, Bogotá, Cundinamarca, Colombia; C. Wouters, MD, PhD, UZ Leuven, Leuven, Belgium; J. Wajdula, PhD, Senior Director, Pfizer Inc., C. Zang, PhD, Associate Director, Pfizer Inc.; J. Bukowski, MD, PhD, Director, Pfizer Inc.; D. Woodworth, MS, Director, Pfizer Inc.; B. Vlahos, MBA, BSN, RN, Senior Director, Pfizer Inc.; A. Martini, MD, University of Genoa, Department of Pediatrics, Genoa, and Istituto Giannina Gaslini, Pediatria II-Reumatologia, PRINTO; N. Ruperto, MD, MPH, Istituto Giannina Gaslini, Pediatria II-Reumatologia, PRINTO.

Address correspondence to Dr. N. Ruperto, Istituto G. Gaslini, Pediatria II, Reumatologia, PRINTO, Via G. Gaslini 5, Genoa 16147, Italy.

E-mail: nicolaruperto@gaslini.org

Accepted for publication December 31, 2015.

Juvenile idiopathic arthritis (JIA) is a common chronic arthritic disease with an incidence of 10 per 100,000 and a prevalence of $80-100 / 100,000$ children $^{1,2,3}$. JIA is heterogeneous, and patients with this disease fall into 1 of 7 categories, as defined by the International League of Associations for Rheumatology, which vary in their signs, symptoms, and prevalence ${ }^{4}$. If not treated appropriately, JIA is often associated with significant pain and disability ${ }^{5,6,7}$

Many treatments are currently available for JIA but few have been studied in selected JIA categories ${ }^{8}$. Anti-tumor necrosis factor (anti-TNF) agents are effective in patients with JIA who are unresponsive to the more traditional disease-modifying antirheumatic drugs (DMARD) such as methotrexate (MTX) $)^{9,10}$. Weekly dosing of the anti-TNF etanercept (ETN) in JIA, either $0.8 \mathrm{mg} / \mathrm{kg}$ once weekly or 0.4 $\mathrm{mg} / \mathrm{kg}$ twice weekly, has achieved response quickly and is sustainable in the long term ${ }^{9,11,12,13}$. Although the efficacy and safety profile of ETN has proven to be favorable, studies have largely grouped patients into JIA as a whole. Our knowledge of the effect of ETN on the individual JIA categories, such as extended oligoarthritis (eoJIA), enthesitis-related arthritis (ERA), or psoriatic arthritis (PsA), is limited, especially in longterm treatment, despite having a relative share of $9 \%, 14 \%$, and $7 \%$ of total JIA cases, respectively ${ }^{14,15}$. Previous studies that have presented data for these specific categories have largely been based on retrospective and/or registry data $16,17,18,19,20$.

Part 1 of the Clinical Study In Paediatric Patients of Etanercept for Treatment of ERA, PsA, and Extended
Oligoarthritis (CLIPPER) study was undertaken to determine the 12-week efficacy and safety of ETN in patients with eoJIA, ERA, and PsA, and for the first time, prospective data were reported in these JIA categories ${ }^{21}$. ETN was shown to be effective after just 12 weeks, with $88.6 \%$ of patients achieving a JIA American College of Rheumatology (ACR) 30 , which is significantly more patients versus placebo data from a historical metaanalysis ${ }^{22}$. The CLIPPER study was continued beyond 12 weeks to 96 weeks in the same population of patients, focusing on longterm efficacy and safety, and the results are presented here.

\section{MATERIALS AND METHODS}

Patients and study design. CLIPPER was a 96-week, phase IIIb, open-label multicenter study performed in 38 centers in 19 countries, including members of the Paediatric Rheumatology International Trials Organisation $\left(\right.$ PRINTO) ${ }^{23}$

Patients with eoJIA (aged 2-17 yrs), ERA (12-17 yrs), or PsA (12-17 yrs) received ETN $0.8 \mathrm{mg} / \mathrm{kg}$ once weekly (QW; max dose, $50 \mathrm{mg}$ ) for up to 96 weeks. Concomitant therapy with only 1 of the following was permitted: MTX, hydroxychloroquine, chloroquine, or sulfasalazine. The key inclusion and exclusion criteria are described in full elsewhere ${ }^{21}$. Briefly, patients were required to have $\geq 2$ active peripheral joints swollen or limitation of motion accompanied by either pain or tenderness. Patients with eoJIA or PsA were required to have had an unsatisfactory response or intolerance to a DMARD. In patients with ERA, an unsatisfactory response or intolerance to either a DMARD or a nonsteroidal antiinflammatory drug was required. Prior treatment with other biologic agents was an exclusion criterion

All parents/patients signed and dated an informed consent form, and the study was approved by the local ethics committee. We conducted our study in compliance with the ethical principles originating in or derived from the Declaration of Helsinki, and in compliance with all International Conference on Harmonisation of Good Clinical Practice Guidelines. It was registered on http://clinicaltrials.gov/ with the identifier NCT00962741.

Assessments. The efficacy endpoints included the proportions of patients achieving JIA ACR 30/50/70/90/100 responses and inactive disease criteria over the 96 weeks. Inactive disease was defined as no joints with active arthritis; no fever, rash, serositis, splenomegaly, or generalized lymphadenopathy attributable to JIA; C-reactive protein (CRP) level within normal limits; a physician's global assessment (PGA) of disease activity score of 0 on a 21-circle visual analog scale (VAS); duration of morning stiffness of $\leq 15 \mathrm{~min}$; and no active uveitis over time ${ }^{24}$. The Juvenile Arthritis Disease Activity Score (JADAS) included these 4 components: physician's global assessment of disease activity ( $0-10 \mathrm{VAS} ; 0=$ no activity, $10=\max$ activity); parent/patient's global assessment of well-being (0-10 VAS; $0=$ very well, $10=$ very poor); count of 27 joints with active disease; and CRP (range $0-57$ ). Inactive disease was defined as JADAS $\leq 1$. The mean (SD) change from baseline was assessed for the JIA ACR core components, parent's global assessment of child's pain VAS ( $\mathrm{mm}$ ), and the duration of morning stiffness in all patients overall and for each JIA category. In addition, mean (SD) change was calculated for the ERA-specific endpoints of prorated tender entheseal score [defined as $66 \times$ (total number of tender entheses with score $>0$ )/number of non-missing tender entheseal assessments; if $>33$ assessments were not recorded, then the overall value was defined as missing], overall back pain ( $\mathrm{mm}$ ), nocturnal back pain ( $\mathrm{mm}$ ), Schober's test $(\mathrm{cm})$, and the PsA-specific endpoints of psoriasis body surface area (BSA; $\%)$ and PGA of psoriasis.

Safety. Treatment-emergent adverse events (AE) and serious treatment-emergent AE were recorded throughout the study. Serum samples were tested for anti-ETN antibodies and neutralizing antibodies.

Statistical analysis. One hundred patients were expected to enroll in the

Personal non-commercial use only. The Journal of Rheumatology Copyright $\subset$ 2016. All rights reserved. 
study and this determined the sample size. It was expected that the half-width of the $95 \%$ CI would be no more than $10 \%$ for estimation of the JIA ACR 30 response rate [the primary endpoint for part 1 (Week 12) of the CLIPPER study]. The modified intention-to-treat (mITT) population was used for both the efficacy and safety analyses and was defined as all patients who received $\geq 1$ dose of ETN. For ACR JIA response rates, in addition to observed cases (OC) data, sensitivity analyses were performed using last observation carried forward (LOCF) imputation of missing data and the non-responder imputation (NRI) method. For the JIA ACR, ACR inactive disease, and JADAS inactive disease response rates, the more conservative NRI data were used; for these analyses "missing" values and all visits after discontinuation were classified as having non-responder status. All other analyses were based on the OC data. Descriptive summary statistics for the OC data were provided for each study endpoint at all timepoints of the study. The trials followed the recommendation of the CONSORT statement, with results reported on the intention-to-treat population ${ }^{25}$

\section{RESULTS}

Patient population. Patient disposition is summarized in Figure 1. The mITT population included 127 patients: 60 with eoJIA, 38 with ERA, and 29 with PsA. Of them, 122 patients $(96 \%)$ entered Part 2 of this study and received treatment for 96 weeks. In total, 109 patients $(85.8 \%)$ completed the study. The demographic characteristics were reported in the previous article ${ }^{21}$. In brief, mean (SD) age at first ETN injection for individual categories was 8.6 years (4.6) for patients with eoJIA, 14.5 years (1.6) for patients with ERA, and 14.5 years (2.0) for patients with PsA. For the eoJIA category, $25.0 \%$ of patients were $2-4$ years, $38.3 \%$ were 5-11 years, and $36.7 \%$ were $12-17$ years. For the ERA and PsA categories, all patients were $12-17$ years of age. The mean (SD) disease duration was 31.6 months (31.7) for patients with eoJIA, 23.0 months (19.8) for patients with ERA, and 21.8 months (20.2) for patients with PsA. The majority of patients were female within the eoJIA (68.3\%) and PsA (79.3\%) categories, but the majority of patients with ERA were male (79.0\%). Prior DMARD (taken at baseline or within 4 weeks prior to the screening visit) were received by $55(91.7 \%)$ patients with eoJIA, $32(84.2 \%)$ patients with ERA, and $24(82.8 \%)$ patients with PsA. Concomitant DMARD were taken by 55 patients (91.7\%) with eoJIA, 32 (84.2\%) with ERA, and 24 (82.8\%) with PsA.

Efficacy. Responses across all JIA ACR levels in general were evident already at Week 12, with incremental increases observed through Week 96, especially for JIA ACR $70 / 90 / 100$. In the overall population, the percentages of patients who achieved JIA ACR 30/50/70/90/100 (95\% CI) responses (NRI data with denominator equal to 127) at Week 12 were $85.8 \%$ (78.5, 91.4), 78.0\% (69.7, 84.8), 59.1\% (50.0, $67.7), 28.3 \%(20.7,37.0)$, and $22.0 \%(15.2,30.3)$, respectively (Figure 2A). These responses continued to increase through to Week 96 with $84.3 \%$ (76.7, 90.1), 83.5\% (75.8, $89.5), 78.7 \%$ (70.6, 85.5), 55.1\% (46.0, 63.9), and $45.7 \%$ $(36.8,54.7)$ of patients overall reaching JIA ACR $30 / 50 / 70 / 90 / 100$, respectively. In patients with eoJIA, the

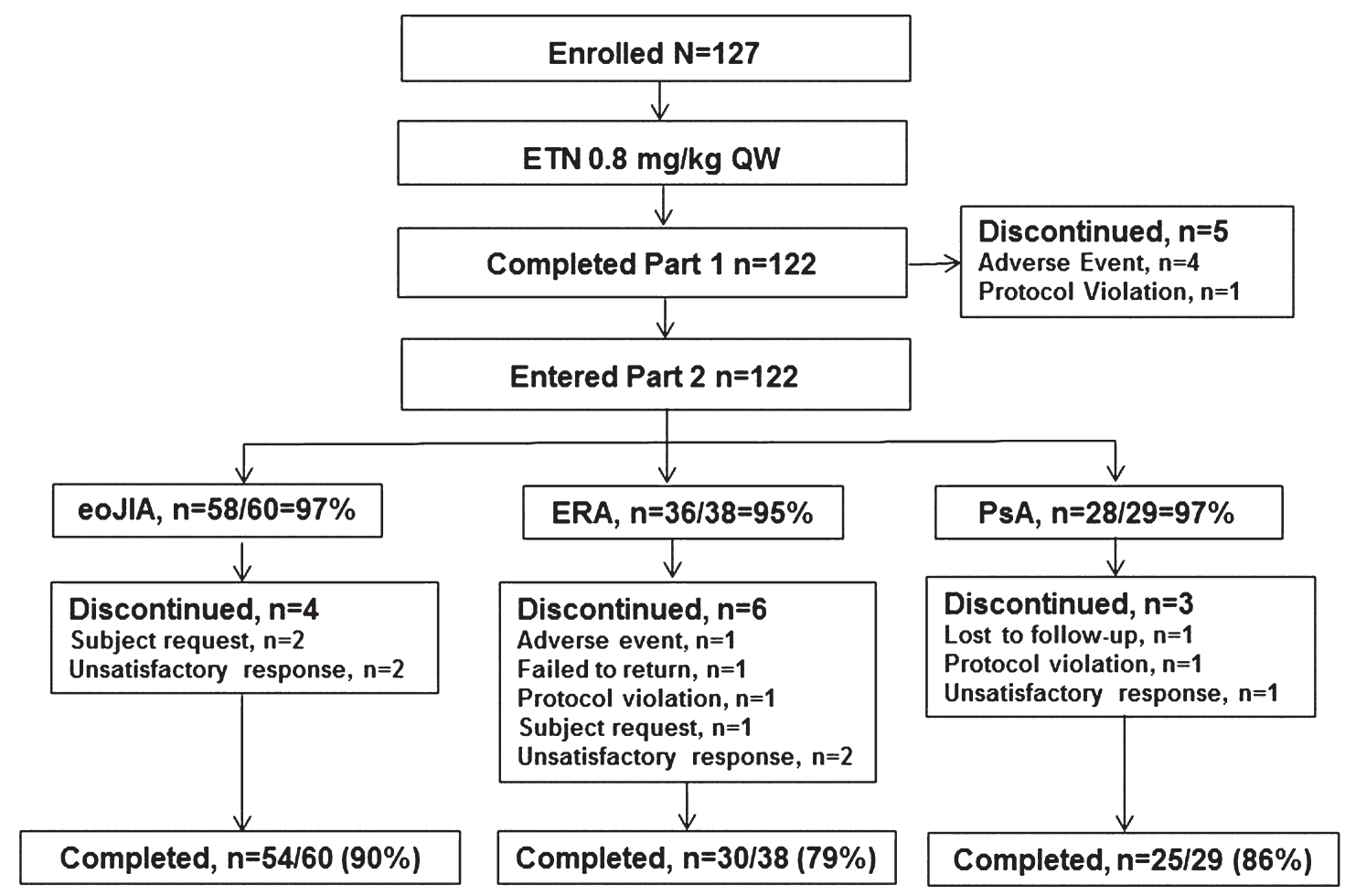

Figure 1. Patient disposition. Adverse events included infections. All subjects who discontinued etanercept (ETN) were monitored for safety for the remainder of the study period. eoJIA: extended oligoarthritis; JIA: juvenile idiopathic arthritis; ERA: enthesitis-related arthritis; PsA: psoriatic arthritis; QW: once weekly. 

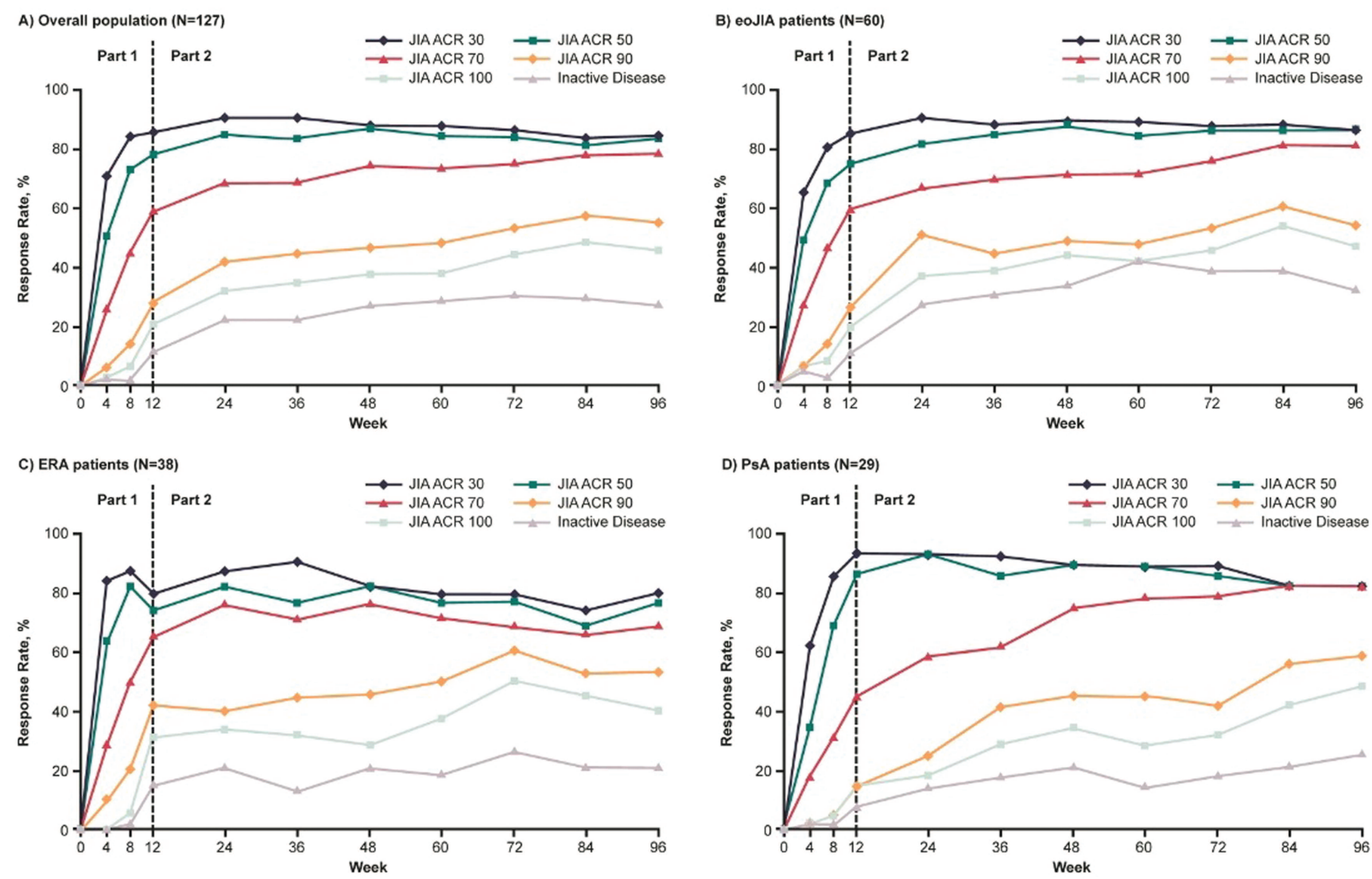

Figure 2. JIA ACR response rates and inactive disease status (NRI data; mITT) over time. A. Overall population. B. eoJIA. C. ERA. D. PsA. Data imputed for 19/127 patients (15.0\%) for the JIA ACR analyses and 21/127 patients (16.5\%) for the inactive disease analyses. eoJIA: extended oligoarthritis; JIA: juvenile idiopathic arthritis; ACR: American College of Rheumatology; ERA: enthesitis-related arthritis; PsA: psoriatic arthritis.

percentages achieving JIA ACR 30/50/70/90/100 responses by Week 96 were $88.3 \%(77.4,95.2), 88.3 \%(77.4,95.2)$, $83.3 \%(71.5,91.7), 55.0 \%(41.6,67.9)$, and $48.3 \%(35.2$, 61.6), respectively (Figure 2B). The proportions of patients with eoJIA achieving JIA ACR responses were consistent across the 3 age groups (data not shown). Patients with ERA achieving JIA ACR 30/50/70/90/100 at Week 96 were 78.9\% $(62.7,90.4), 76.3 \%(59.8,88.6), 68.4 \%(51.3,82.5), 52.6 \%$ $(35.8,69.0)$, and $39.5 \%(24.0,56.6)$, respectively (Figure $2 \mathrm{C})$. These were similar in patients with PsA, with JIA ACR $30 / 50 / 70 / 90 / 100$ response levels at $82.8 \%(64.2,94.2), 82.8 \%$ $(64.2,94.2), 82.8 \%(64.2,94.2), 58.6 \%(38.9,76.5)$, and $48.3 \%(29.4,67.5)$, respectively (Figure 2D). In total, inactive disease $(95 \% \mathrm{CI})$ was achieved by $27.6 \%$ (20.0, $36.2)$ at Week 96 ; and by $33.3 \%(21.7,46.7), 21.1 \%$ (9.6, $37.3)$, and $24.1 \%(10.3,43.5)$ in patients with eoJIA, ERA, and PsA, respectively. The percentages of patients with eoJIA, ERA, and PsA who achieved inactive disease responses were similar at all timepoints. OC data for ACR JIA and inactive disease endpoints, and LOCF data for ACR JIA endpoints, are available in Supplementary Figures 1 and 2 , online at jrheum.org.
JADAS inactive disease was achieved by $14.2 \%$ of the overall population (NRI data with denominator equal to 127) at Week 12, and this proportion had increased to 33.9\% at Week 96. For the individual JIA subgroups, the percentage of patients achieving JADAS inactive disease at Week 96 was $36.7 \%, 23.7 \%$, and $41.4 \%$ in patients with eoJIA, ERA, and PsA, respectively.

Overall, significant changes were observed as early as Week 12 in all JIA ACR components, such as the parent's global assessment of child's pain VAS assessments, the duration of morning stiffness, and in the JADAS (Table 1). These changes continued to improve through Weeks 48 and 96. For each JIA category, substantial changes from baseline at Week 96 were reported in the effectiveness measures analyzed (Table 2).

For ERA-specific measures (tender entheseal score, overall back pain, nocturnal back pain, and Schober's test), all were improved from baseline at Weeks 48 and 96. The psoriasis BSA and PGA of psoriasis, as measured in patients with PsA, were also improved from baseline at Weeks 48 and 96.

Safety. Overall, the events per 100 patient-years for AE were 139.5 (Table 3). The most frequently reported AE (no. events,

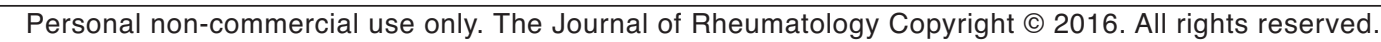


Table 1. Disease characteristics at baseline, and change from baseline at weeks 12, 48, and 96 for all JIA categories.

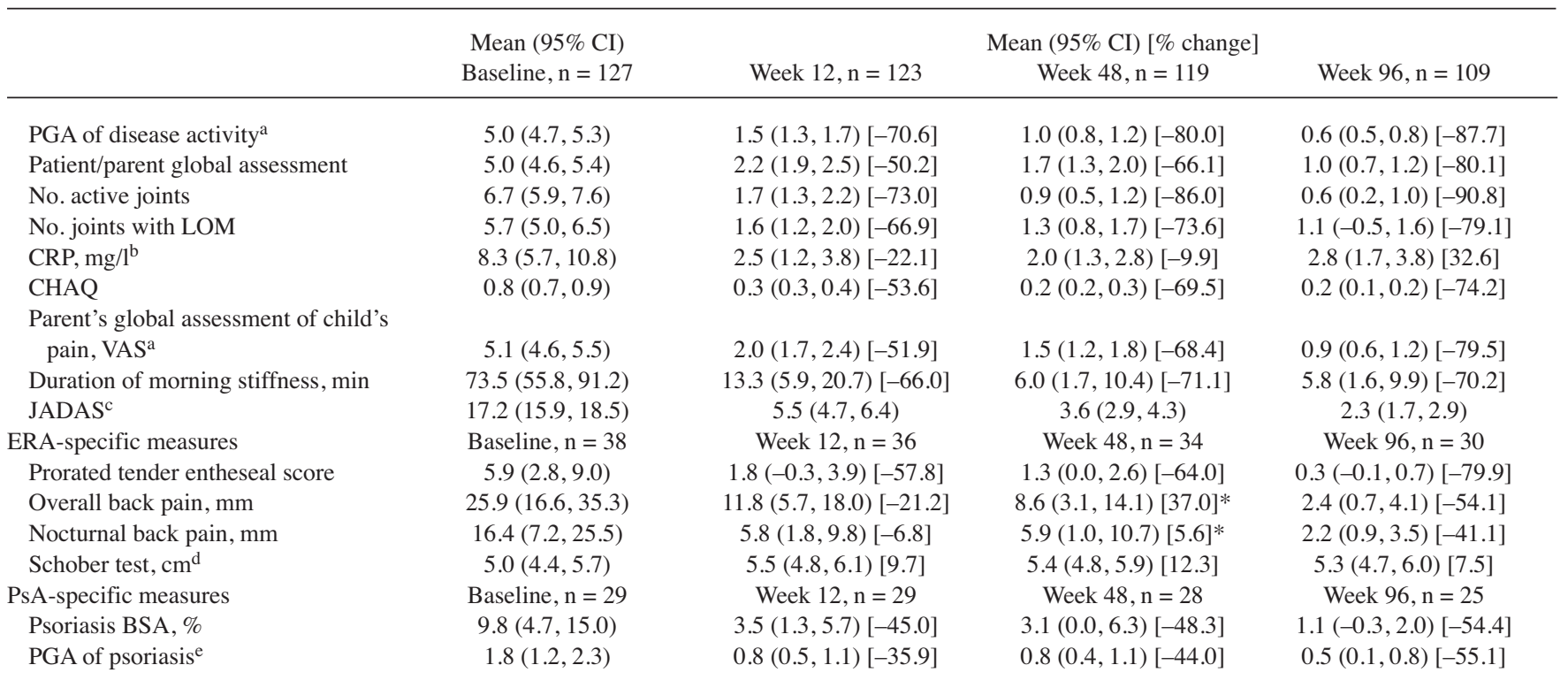

${ }^{*}$ Positive mean $\%$ change at some visits is due to outlier values. ${ }^{\mathrm{a}} \mathrm{n}=108$ for Week $96 .{ }^{\mathrm{b}} \mathrm{n}=120,117$, and 103 for weeks 12,48 , and 96 , respectively. ${ }^{\mathrm{c}} \mathrm{n}=$ $118,120,117$, and 102 for baseline and weeks 12,48, and 96, respectively. ${ }^{\mathrm{d}}$ Modified Schober test values in the table were subtracted 10 from reported values. ${ }^{\mathrm{e}} \mathrm{n}=28$ for Week 12. BSA: body surface area; CHAQ: Childhood Health Assessment Questionnaire; CRP: C-reactive protein; ERA: enthesitis-related arthritis; JADAS: juvenile arthritis disease activity score; JIA: juvenile idiopathic arthritis; LOM: limitation of motion; PGA: physician's global assessment; PsA: psoriatic arthritis; VAS: visual analog scale.

Table 2. Changes in effectiveness measures by categories.



${ }^{*}$ Positive mean $\%$ change at some visits is due to outlier values. ${ }^{\mathrm{a}} \mathrm{n}=53,30$, and 25 for eoJIA, ERA, and PsA, respectively, at Week $96 .{ }^{\mathrm{b}} \mathrm{n}=54,30$, and 25 for eoJIA, ERA, and PsA, respectively, at Week $96 .^{\mathrm{c}} \mathrm{n}=52,27$, and 24 for eoJIA, ERA, and PsA, respectively, at Week $96 .{ }^{\mathrm{d}} \mathrm{n}=55,37$, and 26 for eoJIA, ERA, and PsA, respectively, at baseline, and $\mathrm{n}=51,27$, and 24 at Week 96. CHAQ: Childhood Health Assessment Questionnaire; CRP: C-reactive protein; eoJIA: extended oligoarthritis (in juvenile idiopathic arthritis); ERA: enthesitis-related arthritis; LOM: limitation of motion; JADAS: Juvenile Arthritis Disease Activity Score; PGA: physician's global assessment; PsA: psoriatic arthritis; VAS: visual analog scale.

events per 100 patient-yrs) in the overall population were headache $(23,10.7)$, pyrexia $(12,5.6)$, and diarrhea $(10,4.6)$. All other AE occurred in the overall population at events per 100 patient-year rates of $\leq 3.7$.

The most commonly reported infections (no. events, events per 100 patient-yrs) in the overall population were upper respiratory tract infection $(83,38.6)$, pharyngitis $(50$, $23.2)$, gastroenteritis $(22,10.2)$, bronchitis $(19,8.8)$, and rhinitis $(17,7.9)$; all other infections occurred in the overall population at events per 100 patient-year rates of $\leq 6.5$.

Three patients $(2.4 \%)$ with ERA were withdrawn from treatment because of AE: 1 patient $(2.6 \%)$ who was 


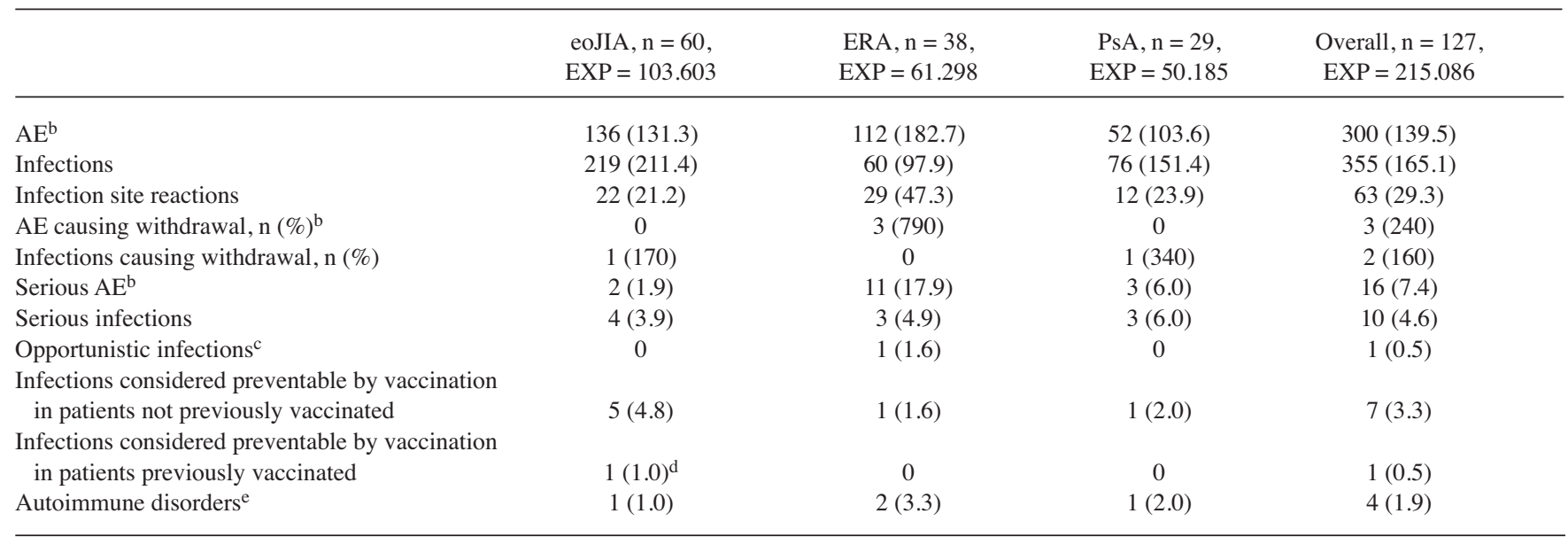

${ }^{\mathrm{a}}$ All values are reported as no. events (events per 100 patient-yrs of EXP to ETN), unless otherwise stated. ${ }^{\mathrm{b}}$ Excluding infections and injection site reactions. ${ }^{\mathrm{c}}$ One case of herpes zoster affecting 2 dermatomes was considered an opportunistic infection and 1 case of latent tuberculosis (purified protein derivative conversion) was not considered an opportunistic infection. For the event of latent tuberculosis, which was not an active case of tuberculosis, ETN and MTX therapy were discontinued, isoniazid was initiated, ETN and MTX therapy were subsequently restarted, and the patient completed the 96-week study. ${ }^{\mathrm{d}}$ One case of rubella. ${ }^{\mathrm{e}}$ Two cases of uveitis (eoJIA and PsA categories), 1 case of iridocyclitis (a type of uveitis; ERA category), and 1 case of Crohn disease (ERA category) were treatment emergent. One case of Crohn's disease (ERA category) was not considered treatment emergent based on missing last-dose data. AE: adverse event; eoJIA: extended oligoarthritis (in juvenile idiopathic arthritis); ERA: enthesitis-related arthritis; ETN: etanercept; EXP: exposure; MTX: methotrexate; PsA: psoriatic arthritis.

HLA-B27-negative had Crohn disease, asthenia, and pyrexia, 1 (2.6\%) had fatigue, dizziness, and wheezing, and $1(2.6 \%)$ withdrew because of JIA exacerbation.

Two patients (1.6\%) withdrew because of infections: 1 patient $(1.7 \%)$ with eoJIA withdrew as a result of bronchopneumonia and $1(3.4 \%)$ with PsA had pyelocystitis.

Ten patients $(7.9 \%)$ had 10 serious infections (4.6 events per 100 patient-yrs). These were gastroenteritis (2 patients), and acute tonsilitis, bronchopneumonia, gastrointestinal infection, helicobacter gastritis, peritonitis, pharyngitis, pyelocystitis, and viral infection (1 patient each).

Two cases of uveitis in patients in the eoJIA and PsA categories were reported. The patient with eoJIA had no reported history of uveitis and reported it after 7.8 months of ETN plus MTX therapy. Dexamethasone eyedrops were used to treat the patient and it was resolved after 42 days. The case of uveitis in the patient with PsA was an exacerbation of chronic uveitis and occurred after 7.8 months of ETN plus MTX therapy. The event was treated with cyclopentolate eyedrops and dexamethasone ophthalmic suspension and resolved after 9 days. One case of iridocyclitis (a form of uveitis) was reported in a patient with ERA after about 1 year of ETN plus MTX therapy; this patient had no reported history of uveitis. The iridocyclitis was treated with cyclopentolate and dexamethasone eyedrops, and phenylephrine ophthalmic solution, and was resolved after 37 days.

In total, 3 cases of Crohn disease were reported, all in patients with ERA. One case was considered possibly related to ETN therapy by the sponsor. This patient was HLA-B27negative, had no history of inflammatory bowel disease or gastrointestinal disorders and was diagnosed after receiving ETN for 21 months. Two cases of Crohn disease were not considered related to ETN therapy. One of these patients (HLA-B27-negative) had a history of weight loss, intermittent diarrhea, fever, and asthenia and was diagnosed with Crohn disease after receiving ETN for 16 days. The patient also was taking concomitant ibuprofen. In response to the events of Crohn disease, asthenia, and fever, ETN was discontinued, with the last dose taken on Day 29. The second case was reported 14 months after the patient discontinued ETN owing to protocol deviation on Day 98, but continued to be monitored for safety. This patient was HLA-B27positive and was receiving concomitant naproxen.

No clinically meaningful differences in the severity of AE or infections were observed across JIA categories. No cases of malignancy, active tuberculosis, demyelinating disorders, or death were reported.

A summary of anti-ETN antibody test results by timepoint is presented in Table 4. None of the patients who were anti-ETN antibody-positive had neutralizing antibodies. Ten patients $(7.9 \%)$ tested positive at 2 timepoints. In those who developed anti-drug antibodies, there were no obvious changes in the effectiveness or safety of ETN.

\section{DISCUSSION}

We have shown single weekly dosing with ETN $0.8 \mathrm{mg} / \mathrm{kg}$ to be effective in treating patients with eoJIA, ERA, and PsA over the course of 96 weeks. This is the first ETN study, to our knowledge, to report prospective longterm efficacy and safety data in patients with these JIA categories. The combi-

Personal non-commercial use only. The Journal of Rheumatology Copyright @ 2016 . All rights reserved. 
Table 4. Anti-ETN antibody status.

\begin{tabular}{lcccc}
\hline \multicolumn{4}{c}{ Patients Testing Positive for Anti-ETN Antibodies } \\
& eoJIA, n/N (\%) & ERA, n/N (\%) & PsA, n/N (\%) & Overall, n/N (\%) \\
\hline Week 12 & $0 / 56$ & $4 / 36(11.1)$ & $2 / 28(7.1)$ & $6 / 120(5.0)$ \\
Week 48 & $7 / 55(12.7)$ & $4 / 34(11.8)$ & $3 / 27(11.1)$ & $14 / 116(12.1)$ \\
Week 96 & $7 / 52(13.5)$ & $3 / 29(10.3)$ & $4 / 24(16.7)$ & $14 / 105(13.3)$ \\
Overall & $11 / 60(18.3)$ & $9 / 38(23.7)$ & $6 / 29(20.7)$ & $26 / 127(20.5)$ \\
\hline
\end{tabular}

eoJIA: extended oligoarthritis (in juvenile idiopathic arthritis); ERA: enthesitis-related arthritis; ETN: etanercept; PsA: psoriatic arthritis.

nation of the dosing method used and the categories studied makes CLIPPER unique.

The JIA ACR and inactive disease responses increased gradually over the course of the study overall and for each of the JIA categories. Specifically, JIA ACR 30 responses were achieved by the majority of patients by Week 12 , and the response was sustained until Week 96. The number of dropouts was low, especially considering the length of the study, which emphasizes the validity of the OC analysis of the efficacy data.

A study using the Biologika in der Kinderrheumatologie (BIKER) registry data analyzed patients with ERA, eoJIA, or PsA receiving ETN $(n=680$ in total) and found lower JIA ACR response rates after 24 months than those reported here ${ }^{20}$. Aside from the BIKER analysis, previous JIA studies have used different timepoints, response measures, or low sample sizes, or have not presented the results separately for each category; therefore direct comparisons are difficult $^{12,16,17,18,19,26,27,28}$. The JIA ACR responses after 12 weeks presented here are similar to those seen in other retrospective ETN studies with eoJIA, ERA, and PsA, and this has been discussed ${ }^{21}$. In studies for which data are available, the proportions of patients achieving JIA ACR responses were also similar for longer timepoints ${ }^{16,17,18}$. A retrospective chart review study into patients taking anti-TNF from an academic center in the United States showed similar levels of inactive disease after 1 year of treatment in patients with eoJIA $(\mathrm{n} / \mathrm{N}=1 / 4 ; 25 \%)$ and ERA $(\mathrm{n} / \mathrm{N}=10 / 42 ; 24 \%)$, but notably higher proportions in patients with $\operatorname{PsA}(\mathrm{n} / \mathrm{N}=6 / 10$; $60 \%$ ), although the number of patients sampled was $\operatorname{low}^{27}$. The majority of patients $(83 \%)$ in the chart review analysis were receiving ETN. An analysis of patients with ERA from a Dutch registry of patients taking anti-TNF showed levels of ACR 30/70 responses similar to those in our study (7/8; $88 \%$ for both) after 27 months; however, the proportion of patients achieving inactive disease was higher $(5 / 8 ; 63 \%)^{19}$. The levels of inactive disease were also higher for a subanalysis of patients with PsA $(5 / 9 ; 56 \%)$ at 27 months from the same Dutch registry ${ }^{18}$. The disparities between our study and others for the inactive disease responses could be due to the lower sample sizes involved. In addition, the older 2004 criteria were used to calculate inactive disease in the other studies $^{29}$.
In patients with ERA, all variables related to active inflammation improved significantly. The magnitude of response for the Schober's test for patients with ERA was less than for the other ERA-specific measures. However, these patients likely had an earlier form of the disease with less axial involvement in lumbar flexion.

Previous studies have investigated the effects of other biologics, such as infliximab (IFX), adalimumab (ADA), or abatacept (ABA) on JIA as a whole $10,30,31,32,33,34$, but to our knowledge none have presented data for specific JIA categories. A small percentage of patients taking IFX (7/125; $6 \%)$ and ADA $(14 / 125 ; 11 \%)$ were reported in the retrospective chart review study of patients with ERA ${ }^{27}$. Similarly, the subanalysis of the Dutch registry of patients with ERA had 2 patients taking ADA and 2 taking IFX ${ }^{19}$; of the patients with PsA from the same registry, only 1 was taking ADA ${ }^{18}$. However, data from these studies were not available for each drug type and the sample sizes involved were too small to allow for a comparison with our study results.

Treatment with ETN was well tolerated and the majority of patients continued treatment for the full 96 weeks. Similar rates of $\mathrm{AE}$, injection site reactions, and infections were observed across all JIA categories, and no new major safety signals were observed. Overall, the average per patient-year for $\mathrm{AE}$ was 1.395 and for serious $\mathrm{AE}$ was 0.074 , similar to previous longterm ETN studies in patients with JIA ${ }^{11,12,16}$. Although 3 patients reported Crohn disease, only 1 was considered potentially related to ETN therapy. Inflammatory bowel disease (IBD) has been associated with juvenile spondyloarthropathies ${ }^{20,35}$; therefore, the increased numbers of IBD in patients with ERA compared with eoJIA or PsA is to be expected. Two patients reported uveitis and 1 patient reported iridocyclitis (a form of uveitis). All of these cases were considered treatment emergent but these are common side effects in patients treated with $\mathrm{ETN}^{36,37}$. In addition, uveitis is common in patients with JIA ${ }^{38,39}$. The BIKER registry study reported several cases of uveitis, which were found to be significantly related to the JIA category ${ }^{20}$. Over the course of 96 weeks, a number of patients $(n=26 ; 20.5 \%)$ tested positive for anti-ETN antibodies; however, none were neutralizing antibodies and there was no obvious effect on efficacy or safety.

Our study was limited by the open-label design and the

Personal non-commercial use only. The Journal of Rheumatology Copyright $\subset$ $\subset$ 2016. All rights reserved 
lack of a placebo control group to act as a comparator. Patients were allowed different concomitant therapies, which may have affected the efficacy and safety results. As the duration of a study increases, the number of patients discontinuing treatment and being lost to followup will also increase and missing data may bias results. For the NRI data applied during our analyses, "missing" values and all visits after discontinuation were classified as having non-responder status, a practice that may have underestimated treatment effects.

ETN $0.8 \mathrm{mg} / \mathrm{kg}$ once weekly was increasingly effective over time for the longterm treatment of patients with eoJIA, ERA, and PsA, and no major safety signals were observed.

\section{ACKNOWLEDGMENT}

We thank all patients who participated in our study, as well as all investigators and medical staff at all of the participating centers. Paper outline and major drafting and revisions were agreed between NR, AM, TC, and Pfizer. Medical writing assistance was provided by Kim Brown and John Bilbruck of Engage Scientific Solutions and was funded by Pfizer.

\section{ONLINE SUPPLEMENT}

Supplementary data for this article are available online at jrheum.org.

\section{REFERENCES}

1. Peterson LS, Mason T, Nelson AM, O'Fallon WM, Gabriel SE. Juvenile rheumatoid arthritis in Rochester, Minnesota 1960-1993. Is the epidemiology changing? Arthritis Rheum 1996;39:1385-90.

2. Manners PJ, Bower C. Worldwide prevalence of juvenile arthritis why does it vary so much? J Rheumatol 2002;29:1520-30.

3. Manners PJ. Epidemiology of the rheumatic diseases of childhood. Curr Rheumatol Rep 2003;5:453-7.

4. Petty RE, Southwood TR, Manners P, Baum J, Glass DN, Goldenberg $\mathrm{J}$, et al. International League of Associations for Rheumatology classification of juvenile idiopathic arthritis: second revision, Edmonton, 2001. J Rheumatol 2004;31:390-2.

5. Prakken B, Albani S, Martini A. Juvenile idiopathic arthritis. Lancet 2011;377:2138-49.

6. Solari N, Viola S, Pistorio A, Magni-Manzoni S, Vitale R, Ruperto $\mathrm{N}$, et al. Assessing current outcomes of juvenile idiopathic arthritis: a cross-sectional study in a tertiary center sample. Arthritis Rheum 2008;59:1571-9.

7. Ringold S, Seidel KD, Koepsell TD, Wallace CA. Inactive disease in polyarticular juvenile idiopathic arthritis: current patterns and associations. Rheumatology 2009;48:972-7.

8. Beukelman T, Patkar NM, Saag KG, Tolleson-Rinehart S, Cron RQ, DeWitt EM, et al. 2011 American College of Rheumatology recommendations for the treatment of juvenile idiopathic arthritis: initiation and safety monitoring of therapeutic agents for the treatment of arthritis and systemic features. Arthritis Care Res 2011;63:465-82.

9. Lovell DJ, Giannini EH, Reiff A, Cawkwell GD, Silverman ED, Nocton JJ, et al. Etanercept in children with polyarticular juvenile rheumatoid arthritis. Pediatric Rheumatology Collaborative Study Group. N Engl J Med 2000;342:763-9.

10. Lovell DJ, Ruperto N, Goodman S, Reiff A, Jung L, Jarosova K, et al. Adalimumab with or without methotrexate in juvenile rheumatoid arthritis. N Engl J Med 2008;359:810-20.

11. Lovell DJ, Reiff A, Ilowite NT, Wallace CA, Chon Y, Lin SL, et al. Safety and efficacy of up to eight years of continuous etanercept therapy in patients with juvenile rheumatoid arthritis. Arthritis Rheum 2008;58:1496-504.
12. Giannini EH, Ilowite NT, Lovell DJ, Wallace CA, Rabinovich CE, Reiff A, et al. Long-term safety and effectiveness of etanercept in children with selected categories of juvenile idiopathic arthritis. Arthritis Rheum 2009;60:2794-804.

13. Kietz DA, Pepmueller PH, Moore TL. Therapeutic use of etanercept in polyarticular course juvenile idiopathic arthritis over a two year period. Ann Rheum Dis 2002;61:171-3.

14. Minden K, Niewerth M. Epidemiology. In: Horneff G, ed. [Juvenile idiopathic arthritis. 2nd edition]. [Book in German] Bremen, London, Boston: UNI-MED Verlag, International Medical Publishers; 2014.

15. Cassidy JT, Petty RE, Laxer RM, Lindsley CB. Textbook of pediatric rheumatology. 2nd edition. Philadelphia: Saunders Elsevier; W.B. Saunders Company; 2010.

16. Prince FH, Twilt M, ten Cate R, van Rossum MA, Armbrust W, Hoppenreijs EP, et al. Long-term follow-up on effectiveness and safety of etanercept in juvenile idiopathic arthritis: the Dutch national register. Ann Rheum Dis 2009;68:635-41.

17. Horneff G, De Bock F, Foeldvari I, Girschick HJ, Michels H, Moebius D, et al. Safety and efficacy of combination of etanercept and methotrexate compared to treatment with etanercept only in patients with juvenile idiopathic arthritis (JIA): preliminary data from the German JIA Registry. Ann Rheum Dis 2009;68:519-25.

18. Otten MH, Prince FH, Ten Cate R, van Rossum MA, Twilt M, Hoppenreijs EP, et al. Tumour necrosis factor (TNF)-blocking agents in juvenile psoriatic arthritis: are they effective? Ann Rheum Dis 2011;70:337-40.

19. Otten MH, Prince FH, Twilt M, Ten Cate R, Armbrust W, Hoppenreijs EP, et al. Tumor necrosis factor-blocking agents for children with enthesitis-related arthritis - data from the Dutch arthritis and biologicals in children register, 1999-2010. J Rheumatol 2011;38:2258-63.

20. Windschall D, Müller T, Becker I, Horneff G. Safety and efficacy of etanercept in children with the JIA categories extended oligoarthritis, enthesitis-related arthritis and psoriasis arthritis. Clin Rheumatol 2014;34:61-9.

21. Horneff G, Burgos-Vargas R, Constantin T, Foeldvari I, Vojinovic J, Chasnyk VG, et al. Efficacy and safety of open-label etanercept on extended oligoarticular juvenile idiopathic arthritis, enthesitis-related arthritis and psoriatic arthritis: part 1 (week 12) of the CLIPPER study. Ann Rheum Dis 2014;73:1114-22.

22. Ruperto N, Pistorio A, Martini A, Sigmund R, Hanft G, Simianer S. A meta-analysis to estimate the "real" placebo effect in juvenile rheumatoid arthritis (JRA) trials. Arthritis Rheum 2003;48:S90.

23. Ruperto N, Martini A. Networking in paediatrics: the example of the Paediatric Rheumatology International Trials Organisation (PRINTO). Arch Dis Child 2011;96:596-601.

24. Wallace CA, Giannini EH, Huang B, Itert L, Ruperto N. American College of Rheumatology provisional criteria for defining clinical inactive disease in select categories of juvenile idiopathic arthritis. Arthritis Care Res 2011;63:929-36.

25. Schulz KF, Altman DG, Moher D, Fergusson D. CONSORT 2010 changes and testing blindness in RCTs. Lancet 2010;375:1144-6.

26. Henrickson M, Reiff A. Prolonged efficacy of etanercept in refractory enthesitis-related arthritis. J Rheumatol 2004;31:2055-61.

27. Donnithorne KJ, Cron RQ, Beukelman T. Attainment of inactive disease status following initiation of TNF-alpha inhibitor therapy for juvenile idiopathic arthritis: enthesitis-related arthritis predicts persistent active disease. J Rheumatol 2011;38:2675-81

28. Tse SM, Burgos-Vargas R, Laxer RM. Anti-tumor necrosis factor alpha blockade in the treatment of juvenile spondylarthropathy. Arthritis Rheum 2005;52:2103-8.

29. Wallace CA, Ruperto N, Giannini E. Preliminary criteria for clinical remission for select categories of juvenile idiopathic arthritis. J Rheumatol 2004;31:2290-4. 
30. Ruperto N, Lovell DJ, Cuttica R, Wilkinson N, Woo P, Espada G, et al. A randomized, placebo-controlled trial of infliximab plus methotrexate for the treatment of polyarticular-course juvenile rheumatoid arthritis. Arthritis Rheum 2007;56:3096-106.

31. Ruperto N, Lovell DJ, Quartier P, Paz E, Rubio-Pérez N, Silva CA, et al. Long-term safety and efficacy of abatacept in children with juvenile idiopathic arthritis. Arthritis Rheum 2010;62:1792-802.

32. Ruperto N, Lovell DJ, Quartier P, Paz E, Rubio-Pérez N, Silva CA, et al. Abatacept in children with juvenile idiopathic arthritis: a randomised, double-blind, placebo-controlled withdrawal trial. Lancet 2008;372:383-91.

33. Lahdenne $P$, Vähäsalo $P$, Honkanen V. Infliximab or etanercept in the treatment of children with refractory juvenile idiopathic arthritis: an open label study. Ann Rheum Dis 2003;62:245-7.

34. Ruperto N, Lovell DJ, Cuttica R, Woo P, Meiorin S, Wouters C, et al. Long-term efficacy and safety of infliximab plus methotrexate for the treatment of polyarticular-course juvenile rheumatoid arthritis: findings from an open-label treatment extension. Ann Rheum Dis 2010;69:718-22.
35. Burgos-Vargas R. Juvenile onset spondyloarthropathies: therapeutic aspects. Ann Rheum Dis 2002;61 Suppl 3:iii33-9.

36. Wang F, Wang NS. Etanercept therapy-associated acute uveitis: a case report and literature review. Clin Exp Rheumatol 2009; 27:838-9.

37. Lim LL, Fraunfelder FW, Rosenbaum JT. Do tumor necrosis factor inhibitors cause uveitis? A registry-based study. Arthritis Rheum 2007;56:3248-52.

38. Saurenmann RK, Levin AV, Feldman BM, Rose JB, Laxer RM, Schneider R, et al. Prevalence, risk factors, and outcome of uveitis in juvenile idiopathic arthritis: a long-term followup study. Arthritis Rheum 2007;56:647-57.

39. Skarin A, Elborgh R, Edlund E, Bengtsson-Stigmar E. Long-term follow-up of patients with uveitis associated with juvenile idiopathic arthritis: a cohort study. Ocul Immunol Inflamm 2009;17:104-8. 